\title{
DRUG-RELATED PROBLEMS IN CHRONIC KIDNEYS DISEASE PATIENTS IN AN INDONESIAN HOSPITAL: DO THE PROBLEMS REALLY MATTER?
}

\author{
HESTY U. RAMADANIATI'1, YUSI ANGGRIANI'1, VONNY M. WOWOR¹, ALVINA RIANTI²
}

${ }^{1}$ Department of Clinical and Community Pharmacy, Faculty of Pharmacy, Pancasila University, Jakarta, Indonesia, ${ }^{2}$ Department of Pharmacy, Fatmawati General Hospital, Jakarta Indonesia

Email: h.ramadaniati@postgrad.curtin.edu.au

Received: 15 Sep 2016 Revised and Accepted: 15 Oct 2016

\begin{abstract}
Objective: To identify and evaluate drug-related problems (DRPs) in patients with chronic kidney disease (CKD).

Methods: A prospective observational three-month study was conducted in adult patients with CKD hospitalised in five general medical wards and one intensive cardiac care unit in a major teaching hospital in Indonesia. Principal researcher (pharmacist) identified the occurrence of DRPs through the direct patient interview, discussion with nurses and assessment of patients' medication charts and medical records. The identified DRPs were validated by a senior pharmacist and classified using Pharmaceutical Care Network Europe/PCNE classification scheme for DRP V6.2. Descriptive analysis was applied for demographic data, drug utilization and DRP profiles.

Results: There were 105 patients who met the inclusion criteria and $80 \%$ of these patients had end-stage renal disease. A total of 2404 medication orders were reviewed and 1026 DRPs were identified. Potential DRPs accounted for around two-thirds of the cases. The rate of overall DRPs was 42.7 DRPs per 100 medication orders and each patient in the study experienced approximately ten DRPs during their hospitalization. Treatment effectiveness and adverse reaction domains contributed to the majority of DRPs primary domains for problems. Drugs for cardiovascular diseases and drugs for correcting electrolyte imbalance were most commonly implicated in DRP incidence.
\end{abstract}

Conclusion: This study uncovered higher rate of DRPs experienced by each patient compared to other CKD studies. There were variations of DRP types when comparing with similar studies. Pharmacists' competencies to identify, prevent and resolve DRPs are vital measures to improve clinical outcomes in CKD patients.

Keywords: Drug-related problems, Chronic kidney disease, PCNE classification

(C) 2016 The Authors. Published by Innovare Academic Sciences Pvt Ltd. This is an open access article under the CC BY license (http://creativecommons.org/licenses/by/4. 0/]

DOI: http://dx.doi.org/10.22159/ijpps.2016v8i12.15193

\section{INTRODUCTION}

Kidney disease is one of global health problems requiring early detection and treatment to prevent its progression [1]. In accordance to reports from World Health Organization (WHO), genitourinary diseases including kidney disease contributed to more than 26 million disability-adjusted life years [2] and were responsible for approximately 800,000 mortality cases each year worldwide [3]. In the United States, the prevalence of end-stage kidney disease was estimated around 1,665 per million population [4], whilst it was reported to be 822 per million population in Australia [5]. In addition, the prevalence of patients receiving renal replacement therapies in European countries ranged between 421 $1,152 /$ million population [6]. In Indonesia, kidney diseases accounted for top five diseases leading to hospitalization and death [7]. Further, kidney disease-related health care costs predominantly burden national health insurance expenses particularly the direct costs attributed to renal replacement therapies (i.e. hemodialysis) for treating chronic kidney disease [8].

Chronic kidney disease (CKD) is characterised by the decline of kidney function within long period [9]. The decline of kidney function causes a range of complications including metabolic abnormalities, endocrine complications and increased risk of cardiovascular diseases. These complications, if not managed appropriately, may implicate on the prolonged length of stay in the hospital and increased mortality rate [10]. Further, CKD was associated with alteration in the pharmacokinetics of a range of drugs in particular renal-excreted drugs. The pharmacokinetic alterations may include the changes in drug bioavailability, protein binding level, drug distribution and elimination. Unfortunately, this condition will make patients become vulnerable to drug-related problems (DRPs). In addition, the progression of CKD may lead to the increased number of medications taken by patients to manage the complications and the comorbidities, and subsequently increase the prevalence of DRPs $[11,12]$

DRP is defined as "an event occurring, as a result, the drug therapy that actually or potentially interferes with desired health outcomes"[13]. It has been evident that the occurrence of DRPs may result in significant morbidity and decrease patients' health-related quality of life in varied clinical settings. In relation to CKD, a range of studies have reported that DRP cases are considerably prevalent and attributed to significant implications [14-17]. Therefore, thorough knowledge of DRPs may benefit health care professionals including pharmacists to identify DRPs, resolve actual DRPs and prevent potential DRPs in order to optimise patients' outcomes. Nonetheless, it is quite unfortunate that limited prospective studies on evaluation of DRPs in patients with chronic kidney diseases have been conducted in Indonesian hospitals. Thus, this study aimed to identify and evaluate drug-related problems (DRPs) in patients with chronic kidney diseases

\section{MATERIALS AND METHODS}

A prospective observational three-month study was conducted in adult patients (18 y or older) who were diagnosed with chronic kidney disease at all stages and hospitalised in five general medical wards and one intensive cardiac care unit in a major teaching hospital in Indonesia. The study protocol was approved by Faculty of Pharmacy Pancasila University Institutional Review Board and Human Ethics Committee at the study hospital (Approval No: DM.03.01/II.3/2226). The patients observed in the study received information sheet prior to consenting to participate.

Data collection was conducted during patient hospitalisation and discharge time. Data collected included date of admission/discharge, patients' socio-demographic data (age, sex, weight, height, type of insurance, smoking status, alcohol/substance abuse, dietary and exercise pattern), comorbidities/past medical history, past 
medication history (including herbal medicines and over-thecounter medicines), allergy/adverse drug reaction history, current medication profiles, discharge medications, laboratory investigations, physical and diagnostic examinations.

Principal researcher (pharmacist) identified the occurrence of DRPs through the direct patient interview, discussion with nurses and assessment of patients' medication charts and medical records. The identified DRPs were validated by a senior pharmacist and classified using Pharmaceutical Care Network Europe/PCNE classification scheme for drug-related problems V6.2 [18]. According to PCNE DRP classification scheme, DRPs were categorised into four primary domains for DRP problems and eight primary domains for DRP causes. The medications prescribed and involved in the DRPs were categorised using Indonesian National Formulary. The rate of DRPs was defined as the rate of DRPs per 100 medication orders and the number of DRPs per each patient. Further, DRPs were divided into actual and potential DRPs.

Demographic data, drug utilisation and DRP profiles were summarised using descriptive statistics (mean \pm standard deviation or median [range] for variables measured on a continuous scale, and frequencies and percentages for categorical variables). Descriptive statistical analysis was carried out using the SPSS $®$ version 22.0 statistical package.

\section{RESULTS}

\section{Demographic characteristics and patients' comorbidities}

There were 105 patients who met the inclusion criteria over the three-month study and the demographic characteristics are summarised in table 1 . On average the patients aged approximately $50 \mathrm{y}$ and there were slightly more female patients. As seen in table 1 , all patients in the present study relied on insurance to cover their health-related expenses where nearly all (94.3\%) were the holder of the national insurance scheme. In addition, the majority of patients (80.0\%) had CKD-V stage with glomerular filtration rate/GFR less than $15 \mathrm{ml} / \mathrm{min} / 1.73 \mathrm{~m}^{2}$ and more than half received hemodialysis. The data also uncovered nearly $90 \%$ of patients were hospitalised once during the study period and there were notable variations in the length of stay with the average duration of hospitalisation was $15 \mathrm{~d}$. In regards, the prevalence of co-morbidities, more than half of the patients had 6-10 other chronic diseases and the most common co-morbid conditions including hypertension, diabetes mellitus, ischemic heart diseases, heart failure and cerebrovascular diseases.

\section{Profile of drug utilisation and DRPs}

There were 2404 medication orders for CKD patients during the study period (table 2). Generic drugs (53.3\%) were prescribed slightly more frequent than their counterparts. As outlined in table 2, cardiovascular drugs accounted for the most common drug classes prescribed, followed by fluid and electrolytes, and drugs for gastrointestinal system. Further, the ten most prevalent drugs prescribed in the study setting included amlodipine, sodium bicarbonate, omeprazole, ceftriaxone, folic acid, vitamin B12, insulin, furosemide, nacetylcysteine and paracetamol. Our data also uncovered that almost $60 \%$ of patients took 6-10 drugs per day, one-third of patients were prescribed more than 10 drugs/day patients leaving just $3.8 \%$ of patients taking less than five drugs/day.

Table 1: Patients' demographic characteristics during the study period $(\mathrm{N}=105)$

\begin{tabular}{|c|c|c|}
\hline Variable & Category & N (\%) \\
\hline \multirow[t]{3}{*}{ Age (years) } & $15-44$ & $30(28.6)$ \\
\hline & $45-64$ & $66(62.9)$ \\
\hline & $\geq 65$ & $9(8.6)$ \\
\hline \multirow[t]{2}{*}{ Sex } & Male & $48(45.7)$ \\
\hline & Female & $57(54.3)$ \\
\hline \multirow[t]{4}{*}{ Body Mass Index } & Underweight & $12(11.4)$ \\
\hline & Normal & $64(60.9)$ \\
\hline & Overweight & $22(20.9)$ \\
\hline & Obesity & $7(6.7)$ \\
\hline \multirow[t]{2}{*}{ Payer } & National Health Insurance & $99(94.3)$ \\
\hline & Private Insurance & $6(5.7)$ \\
\hline \multirow[t]{4}{*}{ CKD stage (according to KDIGO) } & $\begin{array}{l}\text { G3b. Moderately to severely decreased } \\
\text { (GFR } 30-<45 \mathrm{ml} / \mathrm{min} / 1.73 \mathrm{~m}^{2} \text { ) }\end{array}$ & $5(4.8)$ \\
\hline & G4. Severely decreased & $16(15.2)$ \\
\hline & (GFR $15-<30 \mathrm{ml} / \mathrm{min} / 1.73 \mathrm{~m}^{2}$ ) & \\
\hline & G5. Kidney Failure (GFR $<15 \mathrm{ml} / \mathrm{menit} / 1.73 \mathrm{~m}^{2}$ ) & $84(80.0)$ \\
\hline \multirow[t]{2}{*}{ Receiving hemodialysis } & Yes & $62(59.0)$ \\
\hline & No & $43(41.0)$ \\
\hline \multirow[t]{3}{*}{ Hospitalization } & $1 \mathrm{x}$ & $93(88.6)$ \\
\hline & $2 \mathrm{x}$ & $9(8.6)$ \\
\hline & $3 \mathrm{x}$ & $3(2.9)$ \\
\hline \multirow[t]{3}{*}{ Length of Stay (days) } & $\leq 14$ & $52(49.5)$ \\
\hline & $15-28$ & 40 (38.1) \\
\hline & $>28$ & $13(12.4)$ \\
\hline \multirow[t]{4}{*}{ Presence of co-morbidities } & $<5$ & $12(11.4)$ \\
\hline & $6-10$ & $60(57.1)$ \\
\hline & $11-15$ & $28(26.7)$ \\
\hline & $>15$ & $5(4.8)$ \\
\hline
\end{tabular}

eGFR = estimated glomerulus filtration rate, KDIGO = Kidney Disease: Improving Global Outcomes, $\mathrm{n}=$ number of observed patients who met the inclusion criteria (i.e. 105 patients)

A total of 1026 DRP cases were identified, and potential DRPs accounted for around two-thirds of the cases. The rate of overall DRPs was 42.7 DRPs per 100 medication orders. On average, each patient in the study experienced ten DRPs during their hospitalisation. DRP profiles with problems as primary domains identified by the principal researcher are presented in table 3 . As depicted in table 3 , both treatment effectiveness and adverse reaction domains contributed to the majority of DRPs with a similar proportion, whilst domain of treatment costs comprised around 7\% of all DRPs. When conducting further analysis of DRP sub-domains, DRPs related to non-allergic adverse drug events (38.9\%) and sub-optimal effect of drug treatment $(28.7 \%)$ were identified as the two major DRP problems. Most cases of non-allergic adverse drug events were attributed to gastrointestinal bleeding/upset, potassium imbalance and diarrhea. The three major drugs responsible for the non-allergic events were anti-platelets (aspirin, clopidogrel), phosphate binders and laxatives. Meanwhile, 
sub-optimal effect of drug treatment occurred mainly due to the presence of drug-drug interactions and drug-food interactions $(\mathrm{n}=131$ $12.8 \%)$, drugs not taken/administered $(\mathrm{n}=81,7.9 \%)$ and untreated indication $(\mathrm{n}=71,6.9 \%)$ which mostly involved the use of anti- hypertensives (captopril, amlodipine) and calcium carbonate. In addition, the domain of treatment cost was associated with extra costs due to unnecessary treatment with domperidone and paracetamol as the most implicated drugs.

Table 2: Drug classes of medications $(n=2404)$ prescribed for chronic kidney patients

\begin{tabular}{ll}
\hline Therapeutic classes & N (\%) \\
\hline Cardiovascular drugs & $417(17.4)$ \\
Fluid, electrolytes and parenteral nutrition & $380(15.8)$ \\
Gastrointestinal drugs & $284(11.8)$ \\
Anti-infectives & $213(8.9)$ \\
Drugs acting on the Blood or Blood Forming Organ & $206(8.6)$ \\
Vitamins and Minerals & $180(7.5)$ \\
Hormones, endocrine drugs and contraceptives & $170(7.1)$ \\
Diuretics and prostate drug & $159(6.7)$ \\
Respiratory drugs & $144(5.9)$ \\
Analgesic, antipyretic, NSAID and anti-gout agent & $123(5.1)$ \\
Others & $128(5.3)$ \\
\hline
\end{tabular}

$\mathrm{N}=$ number of medication orders during the study (i.e. 2404 medication orders)

Table 4 outlines DRP profiles with causes as primary domains. The selection of drug was the most prevalent cause of DRPs identified by the pharmacist. This domain constituted nearly two-thirds of all DRPs. Further, dose selection was responsible for $37.7 \%$ of DRP cases, followed by drug use process (20.9\%) and logistics (14.4\%).
When analysing DRP sub-domain, there were five major DRP causes included inappropriate combination $(41.8 \%)$, pharmacokinetic problem (14.3\%), drugs not taken/administered (12.6\%), dosage regimen too frequent $(9.3 \%)$ and prescribed drug not available (8.1\%), respectively.

Table 3: The Frequency of drug-related problem/DRP (Primary domains for problems), N=1026

\begin{tabular}{|c|c|c|c|c|}
\hline DRP Domain & DRP sub-domain & Actual DRP & Potential DRP & Total (\%) \\
\hline Problem 1 & P1.1 No effect of drug treatment & 87 & 14 & $101(9.8)$ \\
\hline \multirow[t]{3}{*}{ (Treatment effectiveness) } & P1.2 Effect of drug treatment not optimal & 74 & 220 & $294(28.7)$ \\
\hline & P1.3 Wrong effect of drug treatment & 0 & 0 & 0 \\
\hline & P1.4 Untreated indication & 88 & 0 & $88(8.6)$ \\
\hline Total & & 249 & 234 & $483(47.1 \%)$ \\
\hline Problem 2 & P2.1 Adverse drug event (non-allergic) & 30 & 370 & $400(38.9)$ \\
\hline \multirow[t]{2}{*}{ (Adverse reactions) } & P2.2 Adverse drug event (allergic) & 0 & 6 & $6(0.6)$ \\
\hline & P2.3 Toxic adverse drug event & 1 & 69 & $70(6.8)$ \\
\hline Total & & 31 & 445 & $476(46.4 \%)$ \\
\hline Problem 3 & P3.1 Drug treatment more costly than necessary & 32 & 1 & $33(3.2)$ \\
\hline (Treatment costs) & P3.2 Unnecessary drug treatment & 35 & 0 & $35(3.4)$ \\
\hline Total & & 66 & 1 & $67(6.5)$ \\
\hline
\end{tabular}

$\mathrm{N}=$ Total number of drug-related problems identified (i.e. 1026 drug-related problems)

Table 4: The frequency of drug-related Problem/DRP with causes as primary domains, $\mathrm{N}=1026$

\begin{tabular}{|c|c|c|c|c|}
\hline DRP domain & DRP sub-domain & Actual DRP & Potential DRP & Total (\%) \\
\hline Cause 1 & C1.1 Inappropriate drug & 24 & 32 & $56(5.5)$ \\
\hline \multirow{8}{*}{ Drug selection } & C1.2 No indication for drug & 32 & 3 & $35(3.4)$ \\
\hline & C1.3 Inappropriate combination & 32 & 397 & $429(41.8)$ \\
\hline & C1.4 Inappropriate duplication. & 14 & 18 & $32(3.1)$ \\
\hline & C1.5 Unnoticed indication & 73 & 0 & $73(7.1)$ \\
\hline & C1.6 Too many drugs for indication & 10 & 4 & $14(1.4)$ \\
\hline & C1.7 More cost-effective drug available & 0 & 0 & 0 \\
\hline & C1.8 Synergetic or preventive drug required & 24 & 1 & $25(2.4)$ \\
\hline & C1.9 New indication presented & 18 & 0 & $18(1.8)$ \\
\hline Total & & 227 & 455 & $682(66.5)$ \\
\hline Cause 2 Drug form & C2.1 Inappropriate drug form & 0 & 2 & $2(0.2)$ \\
\hline Total & & 0 & 2 & $2(0.2)$ \\
\hline Cause 3 & C3.1 Drug dose too low & 10 & 22 & $32(3.1)$ \\
\hline \multirow[t]{6}{*}{ Dose selection } & C3.2 Drug dose too high & 2 & 68 & $70(6.8)$ \\
\hline & C3.3 Dosage regimen not frequent enough & 0 & 3 & $3(0.3)$ \\
\hline & C3.4 Dosage regimen too frequent & 3 & 92 & $95(9.3)$ \\
\hline & C3.5 No therapeutic drug monitoring & 0 & 18 & $18(1.8)$ \\
\hline & C3.6 Pharmacokinetic problem & 2 & 145 & $147(14.3)$ \\
\hline & C3.7 Deterioration/improvement of disease & 17 & 5 & $22(2.1)$ \\
\hline Total & & 34 & 353 & $387(37.7)$ \\
\hline Cause 4 & C4.1 Duration of treatment too short & 0 & 0 & 0 \\
\hline Treatment duration & C4.2 Treatment duration too long & 38 & 9 & $47(4.6)$ \\
\hline Total & & 38 & 9 & $47(4.6)$ \\
\hline
\end{tabular}

$\mathrm{N}=$ Total number of drug-related problems identified (i.e. 1026 drug-related problems) 
Table 4: The Frequency of drug-related problem with causes as primary domains (continued)

\begin{tabular}{|c|c|c|c|c|}
\hline Domain & Subdomain & Actual DRP & Potential DRP & total $(\%)$ \\
\hline Cause 5 & C5.1 Patient gets/takes drug on wrong times & 23 & 20 & $43(4.2)$ \\
\hline \multirow{6}{*}{ Drug use process } & C5.2 Drug under used/administered & 5 & 4 & $9(0.9)$ \\
\hline & C5.3 Drug overused/administered & 14 & 17 & $31(3.0)$ \\
\hline & C5.4 Drug not taken/not administered at all & 97 & 32 & $129(12.6)$ \\
\hline & C5.5 Wrong drug taken/administered & 0 & 2 & $2(0.2)$ \\
\hline & C5.6 Drug abused (unregulated overuse) & 0 & 0 & 0 \\
\hline & C5.7 Patient unable to use drug/form as directed & 0 & 0 & 0 \\
\hline Total & & 139 & 75 & $214(20.9)$ \\
\hline Cause 6 & C6.1 Prescribed drug not available & 60 & 23 & $83(8.1)$ \\
\hline \multirow[t]{2}{*}{ Logistics } & C6.2 Prescribing error (information wrong or missing) & 37 & 22 & $59(5.8)$ \\
\hline & C6.3 Dispensing error (wrong drug or dose) & 2 & 4 & $6(0.6)$ \\
\hline Total & & 99 & 49 & $148(14.4)$ \\
\hline Cause 7 & C7.1 Patient forgets to take drug & 0 & 0 & 0 \\
\hline \multirow[t]{3}{*}{ Patient } & C7.2 Patient uses unnecessary drug & 0 & 0 & 0 \\
\hline & C7.3 Patient takes food that interacts & 12 & 5 & 17 (1.7) \\
\hline & C7.4 Patient stored drug inappropriately & 0 & 0 & 0 \\
\hline Total & & 12 & 5 & 17 (1.7) \\
\hline Cause 8 & C8.1 Other cause & 51 & 56 & $107(10.4)$ \\
\hline Other & C8.2 No obvious cause & 0 & 0 & 0 \\
\hline Total & & 51 & 56 & $107(10.4)$ \\
\hline
\end{tabular}

$\mathrm{N}=$ Total number of drug-related problems identified (i.e. 1026 drug-related problems)

\section{DISCUSSION}

During this three-month study, the pharmacist reviewed 2404 medication orders prescribed for 105 patients and identified 1026 DRPs. The rate of DRPs in the present study was 42.7 DRPs per 100 medication orders and approximately ten DRPs for each patient. Potential DRPs accounted for the majority of the cases as opposed to the manifest/actual DRPs. A higher rate of DRPs (81 DRPs per 100 medication orders) was reported from a study conducted in a teaching hospital in India. In addition, that study revealed that there was an upward tendency of DRP incidence in accordance to increased number of medications [19]. When comparing the rate of DRPs experienced by each patient, other studies involving either inpatient or outpatient settings uncovered lower rate which ranged between 1.4-5.0 DRPs/patient [20-25].

With respect to the profile of DRPs, non-allergic adverse drug events and sub-optimal effect of treatment were found as the major primary domains for DRP problems. Additionally, an inappropriate combination of drugs with other drugs or food contributed to the predominant cause of DRPs. These findings were in line with the DRP profiles documented by Rani et al. [19]. However, different DRP patterns were revealed in other studies with dosing-related problems being responsible for the most frequent DRPs [26, 27]. In relation to drugs associated with DRPs, the result of our study were consistent with those of previous studies where drugs for cardiovascular diseases (anti-platelets, anti-hypertensives) and drugs for correcting electrolyte imbalance (i.e. phosphate binders) were most commonly implicated in DRP incidence [20, 23, 25].

The consequences of DRPs have ramifications in CKD patients already burdened by multimodal treatment. It has been well-defined that the consequences of the DRPs result in prolonged hospitalisation, readmissions to the hospital, increased cost and premature death [28, 29]. It is evident that reducing the occurrence of DRPs will lead to better outcomes for patients, and reduce the financial burden [30]. In addition, there may also be great personal costs to those involved and may result in time away from work, low patient satisfaction and decreased public trust toward health care $[31,32]$. Hence, it is of importance to implement effective measures to prevent and resolve DRP occurrence. As the part of health care professionals, pharmacists are best positioned to ensure that medications are used rationally and safely, increase awareness of DRPs, prevent and resolve the problems. The traditional role of pharmacists particularly in hospitals (e. g. compounding, dispensing and supply of medicines) has expanded to include clinical activities. This transition has increased the contribution of pharmacists as part of healthcare teams in minimising DRPs and optimising patient outcomes [33]. Understandably, the role of clinical pharmacists has been well-defined to improve patient safety and minimise any harm related to medication use in numerous clinical settings. Substantial savings can be made by maximising the competencies of pharmacists and implementing pharmaceutical care [34-37]. The results of the present study specifically support the established evidence that clinical pharmacists through identification, prevention and resolution of DRPs are able to provide quality patient care and ultimately improve desired clinical outcomes in patients with CKD [25, 38, 39].

The nature of prospective observation in this study offers more opportunities to capture DRPs in comparison to the retrospective method. In addition, the real-time measures through prevention of potential DRPs and resolution of actual DRPs benefit the patients during the study; not merely providing the data of rate and nature of DRPs. However, a number of limitations need to be acknowledged. This study was conducted in one hospital which diminishes the generalizability of the findings. Another limitation is the difficulty in drawing accurate comparisons with other DRP studies due to considerable variations in settings, design, duration, size and method.

\section{CONCLUSION}

This study uncovered higher rate of DRPs experienced by each patient compared to other CKD studies. In terms of types of DRPs, this study showed varied results as opposed to other CKD studies. The nature of prospective observation offers more opportunities to capture DRPs and to intercept potential DRPs. This study also justified the evident that pharmacists' competencies to identify DRPs, prevent potential DRPs and resolve actual DRPs are vital measures to improve clinical outcomes in CKD patients.

\section{CONFLICT OF INTERESTS}

The authors have none to declare

\section{REFERENCES}

1. National Kidney F. K/DOQI clinical practice guidelines for chronic kidney disease: evaluation, classification, and stratification. Am J Kidney Dis 2002;39:S1-266.

2. WHO. Global Health Estimates Summary tables: DALYs by Cause, Age, and SEX. Geneva, Switzerland: World Health Organization; 2013.

3. WHO. Global Health Estimates Summary tables: Death by Cause, Age, and Sex. Geneva, Switzerland; 2013.

4. USRDS. Atlas of end-stage renal disease. Minneapolis: USRDS; 2009.

5. Australia and New Zealand Dialysis and Transplant Registry. ANZDATA Registry. Melbourne: 2009.

6. ERA-EDTA Registry. ERA-EDTA registry annual report. Amsterdam: ERA-EDTA Registry; 2009. 
7. Pusat Data dan Informasi Kesehatan Kementerian Kesehatan Republik Indonesia. Buletin jendela data dan informasi kesehatan. Jakarta: Kementerian Kesehatan Republik Indonesia; 2012.

8. Klaim penyakit [press release]. Jakarta: Badan Penyelenggara Jaminan Sosial; 2015.

9. Maxine A, Papadakis M, Stephen J, McPhess M. Current medical diagnosis and treatment. 52 ed. New York: The Mc Graw-Hill Companies; 2013.

10. National Kidney F. KDIGO 2012 clinical practice guideline for the evaluation and management of chronic kidney disease. J Int Soc Nephrol 2013;3:4-17.

11. Koda-Kimble MA, Young LY, Alldredge SK, Corelli RL, Guglielmo BJ, Kradjan WA. Applied therapeutics: the clinical use of drugs. 9 ed. Philadelphia: Lippincott Williams and Wilkins; 2009.

12. Mason NA, Bakus JL. Strategies for reducing polypharmacy and other medication-related problems in chronic kidney disease. Semin Dial 2010;23:55-61.

13. Strand LM, Morley PC, Cipolle RJ, Ramsey R, Lamas GD. Drugrelated problems: their structure and function. Ann Pharmacother 1990;24:1093-7.

14. Emami S, Esfahani HR, Farukhi FR, Fahimi F. Assessment of drug dose adjustment in patients with kidney disease: opportunities of pharmacist involvement. Int J Pharm Pharm Sci 2012;4:178-81.

15. Alahdal AM, Elberry AA. Evaluation of applying drug dose adjustment by physicians in patients with renal impairment. Saudi Pharm J 2012;20:217-20.

16. Decloedt E, Leisegan R, Blockman M, Cohen K. Dosage adjustment in medical patients with renal impairment at Groote Schuur Hospital. South Afr Med J 2010;100:304-6.

17. Markota NP, Markota I, Tomic M, Zelenik A. Inappropriate drug dosage adjustments in patients with renal impairment. J Nephrol 2009;22:497-501.

18. Pharmaceutical Care Network Europe Foundation. Classification for drug related problems V6.2. Zuidlaren: Pharmaceutical Care Network Europe Foundation; 2010.

19. Rani NV, Thomas R, Rohini E, Soundararajan P, Kannan G, Thennarasu P. A study on drug-related problems in chronic kidney disease patients of a tertiary care teaching hospital in South India. World J Pharm Res 2014;3:1403-17.

20. Possidente CJ, Bailie GR, Hood V. Disruptions in drug therapy in long-term dialysis patients who require hospitalisation. Am J Health-Syst Pharm 1999;56:1961-4.

21. Lim SB, Lim GK, Khog AL, Sivaraman P. Evaluation of the clinical and economic impact through a focused drug therapy review program in in-flight patients with renal impairment. ASHP Midyear Clinical Meeting; 2008. p. 373.

22. Patel HR, Pruchnicki MC, Hall LE. Assessment of chronic kidney disease service in high-risk patients at community health clinic. Ann Pharmacother 2005;39:22-7.

23. Grabe DW, Low CL, Baille GR, Eisele G. Evaluation of drug related problems in an outpatient hemodialysis unit and the impact of a clinical pharmacist. Clin Nephrol 1997;47:117-21.

24. Mirkov S. Implementation of a pharmacist medication review clinic for haemodialysis patients. N Z Med J 2009;122:25-37.
25. Pal AB, Boyd A, Depczynsky J, Chavez IM, Khan N, Manley H. Reduced drug use and hospitalisation rates in patients undergoing hemodialysis who received pharmaceutical care: a 2-year randomised controlled study. Pharmacotherapy 2009;29:1433-40.

26. Ossman DH, Marouf BH, Ameen KH. Identification of drugrelated problems in patients with chronic kidney disease maintained on hemodialysis in Sulaimani City. J Pharm Sci Innov 2015;4:172-5.

27. Belaiche S, Romanet T, Allenet B, Calop J, Zaoui P. Identification of drug-related problems in ambulatory chronic kidney disease patients: a 6-month prospective study. J Nephrol 2012;25:782-8.

28. Classen DC, Pesstotnik SL, Evans ES, Lloyd JF, Burke JP. Adverse drug events in hospitalised patients: excess length of stay, extra costs and attributable mortality. JAMA 1997;277:301-6.

29. Bates DW, Spell N, Cullen DJ. The costs of adverse drug events in hospitalised patients. JAMA 1997;277:307-11.

30. Australian Institute of Health and Welfare. Australian Hospital Statistics 1999-00. Canberra; 2002.

31. Bates DW, Cullen DJ, Laird N, Petersen LA, Small SD, Servi D, et al. Incidence of adverse drug events and potential adverse drug events. JAMA 1995;274:29-34.

32. Kaushal R, Bates DW, Landrigan C, McKenna KJ, Clapp MD, Federico F, et al. Medication errors and adverse drug events in pediatric inpatients. JAMA 2001;285:2114-20.

33. Lau PM, Stewart K, Dooley M. The ten most common adverse drug reactions (ADRs) in oncology patients: do they matter to you? Support Care Cancer 2004;12:626-33.

34. Johnson JA, Bootman JL. Drug-related morbidity and mortality and the economic impact of pharmaceutical care. Am J HealthSyst Pharm 1997;54:554-8.

35. Umar NF, Joel JJ, Sharma R, Shastry CS, Adepo R. Significant role of clinical pharmacists in the assessment of inappropriate medications prescribed to the elderly patients ina university teaching hospital. Asian J Pharm Clin Res 2015;8:109-12.

36. Karthikeyan G, Ranganayakulu D. Benefits of clinical pharmacist pharmaceutical care interventions to the quality of patients life and control hypertension. Asian J Pharm Clin Res 2014;7:223-6.

37. Rani V. Impact of clinical pharmacist provided education on medication knowledge and adherence of hemodialysis patients in a South Indian University Hospital. Asian J Pharm Clin Res 2013;6:24-7.

38. Stemer G, Lemmens-Gruber R. Clinical pharmacy services and solid organ transplantation: a literature review. Pharm World Sci 2010;32:7-18

39. Kimura $T$, Arai M, Masuda H, Kawabata A. Impact of a pharmacist-implemented anemia management in outpatient with end-stage renal disease in Japan. Biol Pharm Bull 2004;27:1831-3.

\section{How to cite this article}

- Hesty U Ramadaniati, Yusi Anggriani, Vonny M Wowor, Alvina Rianti. Drug-related problems in chronic kidneys disease patients in an Indonesian hospital: do the problems really matter? Int J Pharm Pharm Sci 2016;8(12):298-302. 